\title{
FUNÇÕES TEXTUAIS-INTERATIVAS DOS MARCADORES DISCURSIVOS
}

\section{Clemilton Lopes Pinheiro *}

Resumo: O objetivo deste trabalho é ilustrar algumas das funções articuladoras e interacionais que os marcadores discursivos exercem, conjuntamente, na construção do texto, seguindo, assim, uma perspectiva Funcionalista de abordagem do texto.

Palavras-chave: Marcadores discursivos. Organização textual Topicalidade.

\section{Introdução}

A classe designada como marcadores discursivos inclui elementos fortemente seqüenciadores e interativos. Nesse sentido, investigo, neste trabalho, a integração das funções formulativas e interacionais que os marcadores discursivos exercem na construção global do texto.

Parto da concepção de topicalidade como um princípio de organização geral do texto que apresenta, no plano de sua realização, uma estrutura passível de ser identificada e descrita, e adoto o tópico discursivo como categoria analítica. A análise da organização tópica leva em consideração a identificação e delimitação de segmentos tópicos e dos procedimentos pelos quais esses segmentos se distribuem na linearidade do texto e se recobrem hierarquicamente. Disso se conclui que o texto se organiza topicamente em dois planos: um vertical, que diz respeito à particularização hierarquizada do assunto em pauta; e um horizontal, que diz respeito à distribuição dos tópicos na linha discursiva.

- Professor da Faculdade de Letras (FALE) da Universidade Federal de Alagoas (UFAL), doutor em Lingüística pela UNESP. 
A articulação tópica constitui uma estratégia através da qual se relacionam, na superfície textual, os segmentos tópicos, considerados a partir dos diferentes planos hierárquicos, nível intertópico, e os enunciados que integram os segmentos em particular, nível intratópico. O emprego de marcadores discursivos constitui um dos mecanismos pelos quais se realiza essa estratégia. Eles realizam, tanto no plano da constituição interna dos segmentos tópicos mínimos, intratópico, como no plano da articulação desses segmentos entre si, intertópico, movimentos que sinalizam a construção textual, relacionados a diversos aspectos do processo interacional (PINHEIRO, 2003).

O enfoque teórico adotado é o textual-interativo, segundo o qual, no sistema de desempenho lingüístico, as estruturas lingüísticas e as formas de processamento se integram num só conjunto. O texto é visto como algo simultaneamente estruturado e emergente. Os dados pragmático-situacionais se introjetam no texto, de forma que o interacional é inerente ao lingüístico (KOCH et al., 1994). Tratase, portanto, de uma noção teórica que está inteiramente contida nas propostas teóricas do Funcionalismo Lingüístico, conforme aponta Neves (2003).

\section{A classe dos marcadores discursivos}

Os marcadores discursivos são elementos lingüísticos a que se faz referência nos estudos sobre a ligação de entre partes do texto. Risso, Silva e Urbano (1996, p. 55-6) apresentam a seguinte definição para esses elementos:

[...] mecanismos verbais da enunciação, atuam no plano da organização textual-interativa, com funções normalmente distribuídas entre a projeção das relações interpessoais - quando o foco funcional não está na seqüência entre de partes do texto, e a proeminência da articulação textual - quando a dominante deixa de estar no eixo da interação. 
Esses autores depreenderam as regularidades constantes em ocorrências de marcadores, em quinze inquéritos do Projeto NURC-Br, e propuseram matizes de traços que dão suporte a uma delimitação dessa classe de elementos. Os dados apurados apontaram para as seguintes características:

a) atuam no plano da organização textual-interativa, com tônica na função de articulação entre segmentos textuais ou na sinalização de relações interpessoais;

b) são exteriores ao conteúdo informativo do tópico;

c) não são transparentes do ponto de vista semântico-referencial;

d) apresentam pouca variação fonológica, flexional ou sintática;

e) são sintaticamente independentes;

f) geralmente, acompanham-se de uma pauta prosódica demarcativa, bem definida;

g) apresentam massa fônica reduzida.

Esses traços foram tomados como critérios para o estabelecimento de um núcleo-piloto que define um contínuo de marcadores prototípicos, não prototípicos e unidades limítrofes à classe. O preenchimento ou afastamento gradativo de combinações desses traços serve de critério para enquadrar um dado elemento em algum dos pontos desse contínuo. O subconjunto de marcadores discursivos prototípicos, assim definidos por apresentarem combinações de traços estatisticamente relevantes, inclui elementos fortemente seqüenciadores e interativos, ou seja, exercem, conjuntamente, na construção do texto, funções articuladoras e interacionais.

No que diz respeito à função organizadora, os marcadores atuam nos processos de seqüienciação, retomada ou mudança tópica, seja no nível intertópico ou intratópico. A essa função de organizador da estruturação do texto se congregam outras, de natureza interacional. 


\section{As funções formulativos-interacionais dos marcadores discursivos}

Apresento, neste item, alguns exemplos ilustrativos da integração das funções formulativas e interacionais dos marcadores discursivos. Os dados foram retirados de um corpus bastante diversificado em termos de gêneros textuais e de modalidade falada e escrita. Alguns exemplares dos textos foram extraídos do corpus do Projeto PORCUFORT ${ }^{1}$, alguns do corpus do NELFE².

\subsection{Seqüenciação tópica}

Enquanto seqüenciadores, os marcadores exercem a função textual de integrar tópicos e enunciados dispostos de forma contígua na linearidade do texto e orientar a atenção do ouvinte/leitor para as partes que compõem o texto, tendo em vista facilitar o acompanhamento do desenrolar da informação. Essas partes podem ser os eventos de uma narração, as fases de uma descrição ou exposição, ou as etapas de uma argumentação.

O trecho (01) é um fragmento do segmento 8, da conversação espontânea D2-303, que recobre o tópico Trabalho da Inf. 1. Nesse segmento, a informante faz uma descrição da sua atividade profissional. As fases dessa descrição são delimitadas pelos marcadores então e aí, algumas vezes combinados entre si ou com o $e$. Esses marcadores atuam integradamente no movimento textual

O Projeto PORCUFORT (Português Oral Culto de Fortaleza) constitui uma aplicação, na cidade de Fortaleza-CE, do projeto NURC (Norma Urbana Culta), cujo objetivo é a descrição do português falado culto no Brasil. Os inquéritos são distribuídos de acordo com o sexo e a faixa etária dos informantes e com o grau de formalidade.

2 O NELFE (Núcleo de Estudos da Língua Falada e Escrita) é um núcleo de pesquisa cadastrado no Diretório de Grupos de Pesquisas do CNPq, inserido no programa de Pós-Graduação em Lingüística da UFPE (Universidade Federal de Pernambuco). O objetivo central do núcleo é investigar questōes ligadas à fala e à escrita.

Os textos foram retirados de dois corpora: PORCUFORT (Português Oral Culto de Fortaleza) e NELFE (Núcleo de Estudos da Língua Falada e Escrita - UFPE). 
articulador e no movimento interacional de guiar a atenção do interlocutor para a organização da informação ${ }^{4}$.

[8 Inf. 1 - BOM então deix/ eu falar agora do meu traBAlho \{da minha pra::

Inf. 2 - $\quad$ é acho bom né?

Inf. 1 - ...né?... falar um pouquinho

Inf. $2-((r i)) \ldots$

Inf. 1 - bom... aPESAR da gente ser técnico operacional né? eu e ela a gente... técnico operacional mas desenvolve... eu acho queé só na nomenclatura porque cada qual desenvolve um trabalho \{diferente do outro né?...

Inf. 2 - ((tosse))

Inf. 1 - enTÃO como eu a minha formação é em HisTÓria... então:: eu busco sempre procuRAR... as FONtes de pesquisa né?... então eu vim:: aqui para o SINE e notei que os::.... os pesquisadores que são TOdos econoMIStas... tinha NAda a ver comigo...

Inf.2 - pensadores $\{(($ riu $))$

Inf.1- é os pensadores... e incluSIve:: eu costumo dizer que aqui também tem muito é fiLÓsofo e pouco economista né? porque na verDAde a gente desenvolve mais um trabalho de filosofia do que propriamentede

Inf. 2 - econo\{mia

Inf. 1 - economista... enTÃO... eh:: eu pensei numa maNEIra... de:: suPRIR... as necessiDAdes... DEles... em relação à economia...

4 Os vários empregos do "então" e do "aí", nesse trecho, exercem diferentes funçōes textuais-interativas. No entanto, estou focalizando apenas os que estão sendo usados para marcar as fases da descrição da atividade profissional da informante, em negrito na transcrição. As outras funçōes, como a retomada após inserção parentética, serão tratadas, nos itens seguintes. Há também alguns usos, no trecho em destaque, que, pela grande reincidência, parecem idiossincráticos. 
então:.... eu vinha duma:: dum:: dum traBAlho... que era um trabalho de pesquisa... em cima de jornais... né? então relacionado à História e aqui então eu transformei... esse traBAlho... PARA... o lado da:: Economia... economia trabalho emPREgo desemprego... PIB... e:: outras VAriante de economia né?... e então eu leio... por dia aQUI os jornais... O DIÁrio... A Tribuna Inf. 2 - Follha...

Inf. 1 - O Povo... A Folha... A Gazeta Mercantil e o Jornal do Brasil... então a gente faz... de todo esse jornais... a gente faz uma triAgem... e seleciona... todo esses jornais... então reCORta... aquilo ali é colocado numa FIcha... e aquela ficha... ela é... ela:: é cadastrada... com um NÚmero... e um assunto... então no fiNAL... do MÊS no final dos trinta dias... eh:: eh... a gente junta TOdo esse materiAL... faz uma SEleção desse materiAL... e então publica um boletim... interno... sobre TOdos os assuntos que circularam...

Inf.2 - durante o mês

Inf. 1 - durante aque $\{$ le mês

Inf.2- EU/tava até vendo ontem chegou né? na minha mesa... Inf.1-é

Inf. 2 - aí sai assim... o primeiro foi assim... "URV... eh:: vai muDAR dia tal tal tal" eu digo "valha como chega atrasado" chega atrasado que eu digo logicamente que aquilo a $\{\mathrm{li}$

Inf.1- é porque a gente FAZ

Inf.2- aquilo é um resumo do mês inteiro\{né?

Inf.1-do mês passado sem\{pré o mês anterior Inf.2- ((tosse))é... aí eu achei até engraçado...

Inf. 1 - enTÃO agora no fiNAL ... aí nós temos as tabelas... então:: são:.... são em torno de OIto tabelas... aí tem a cotação... diÁria do dólar... a cotação da URV... a cotação da TR... né?... tem o o:: MerCAdo... eh eh:: as taBElas sobre emPREgo... sobre desemprego... sobre sobre emprego em Fortaleza... emprego no 
interior... e eh::... sobre desemPREgo nas capiTAIS... nas grandes capitais... Produto Interno Bruto... Produto Interno Bruto do Ceará então tudo isso... eh:: per capta... então todas essas informações que são::... eh:: relacionadas ao trabalho... do trabalhador... seguRANça do trabalho... QUALIDAde do trabalho... TOdo tudo isso a gente...publica nesse boletim mensal... Inf.2((tosse $))$

Inf. 1 - E O que não é publiCAdo... é passado... PAra... quer dizer é resumido e publicado o que não é... publiCAdo... porque:: Isso a gente FAZ uma média de oitenta a cem artigos por MÊS... e a gente só publica... cinco ou seis porque... se não fica muito extenso...

Inf.2 -porque tem que resumir ao má\{ximo né?

Inf.1- tem que resumir ao máximo... e então o restante... repassado... exatamente para os TÉCnico... que:: elaBOram... os boletins menSAIS... trimestrais semestrais e anuais do SINE... aí então isso AÍ... SERve de emBAsamento... quer dizer NUM É que eles vão publicar o que tem ali mas a leiTUra... daquele conteúdo possibilita uma:.... formação de uma BAse... para que seja escrito:: o artigo que ele... /tá pensando né?... a iDÉia... e ÀS vezes ele já tem a iDÉIa... porque ele SAbe... que HOUve... uma... digamos esTÁ haVENdo:: um momento de desemprego na faixa etária entre trinta a quarenta anos... e naquele jorNAL... TEM alguma coisa falando daquilo então o jornal passa a ser o subSÍdio... do ARtigo que ele vai escrever né?... seria mais ou menos isso...

(Conversação espontânea, D2-30)

Do movimento textual de seqüenciação, estabelecido por meio de marcadores discursivos, além da orientação da ordem seqüencial em que os segmentos tópicos ou seus enunciados são apresentados e desenvolvidos no discurso, indicando a progressão, emergem outros tipos de relações discursivas, como as de ressalva, reforço, inferência, conseqüência e acordo. 
No trecho (02) da palestra EF-53, na articulação intratópica se instaura uma relação de ressalva. $O$ assunto abordado pela palestrante é a posição dos lingüistas de orientação funcionalista acerca da transitividade, tópico Ternière, segmento 11. Em um conjunto de enunciados, é mostrado que, segundo essa orientação, "a estrutura lingüística existe em razão da função". A palestrante compreende que a palavra "função" tem diferentes acepções. Tratase de uma informação que pode ou não ser conhecida pelos seus interlocutores, e por isso ela julga necessário ressalvar de que forma os lingüistas funcionalistas concebem o termo "função". Essa ressalva é feita no conjunto de enunciados subseqüente, iniciado pelo marcador "mas". A relação de ressalva co-ocorre com o movimento textual articulador, e ambos se instauram no espaço da interação, já que se estabelecem em função do julgamento que a palestrante fez sobre a informação pragmática que seus interlocutores possuíam.

[11 posição dos funcionalistas... TerniÈre Halliday e Dick... Simon Dick... TerniÈre..." a estrutura existe em razão da função... e a função serve ao mecanismo da expressão do pensamento"... embora Ternière tenha... eh::... exisTIdo... viVIdo... no AUge do estruturalismo ortodoxo... a posição dele é já é basTANte diferente... do estruturalismo de Hjelmslev... então pra ELE... a a estrutura eXISte em função da razão em si... ah oh... desculpe ((ri)) em razão da função ((falou rindo))... mas... FUNÇÃO pra Ele... não é a mesma coisa que função para o Hjelmslev... para o Hjelmslev função era FORma... né?... então "a função serve ao mecaNISmo de expressão do pensamento"... então... JÁ ele já comeÇOU... a introduzir... BAses seMÂNticas pra uma análise... da sintaxe né?... (...)

(Palestra, EF-25) 
No exemplo (03), ocorre um caso também de articulação intratópica em que se estabelece uma relação de reforço. No tópico Solução para superar a dificuldade, segmento 13 , a locutora opina sobre uma maneira de superar a dificuldade de falar em público e sugere que é preciso buscar sempre "novos caminhos, novos rumos", dando um exemplo próprio de como buscar esses novos caminhos. Um conjunto de enunciados, o que compõe o exemplo, é usado para reforçar outro, o que expressa a opinião. Essa relação de reforço e exemplificação está integrada à de seqüenciação, na qual reside a articulação intratópica, realizada através do marcador discursivo "por exemplo". Essa relação não é inerente aos enunciados, ao contrário, é interacionalmente, construída, ou seja, trata-se da maneira como a locutora pretende que sua interlocutora perceba as informações, nesse contexto.

Inf. 2 - ((risos))

Inf. 1 - sem PARAR né?... mas... eu sinto uma dificuldade sim... a memória não me ajuda muito não mais... as coisas que eu estudei já muitas vezes eu esqueço... mas é isso mesmo] [ 13 mas a gente vai adiante vai LENdo sempre lendo lendo e procurando... novos:: novos caminhos novos novos rumos

Inf. 2 - NOvos rumos...

Inf. 1 - exatamente...

Inf. 2 -e \{ vai encontrar né?

Inf. 1 - e É ISSO QUE EU... é isso que eu tenho encontrado... por exemplo na igreja... pra mim graças a Deus... o:.... esta Renovação CarisMÁtica... né?... me tem::: dado muitas oportunidades:: e isto é BOM... porque acomodada também como eu sou... EU como certeza... estaria HOJE SÓ em casa... porque não gosto de sair... num gosto de passear num gosto de diversão... então eu estaria em CAsa somente lendo lendo lendo lendo lendo pra meu deleite e pra... e pra ficar com aquilo pra mim somente e 
num levar mais nada pra ninguém mas assim... mas graças a Deus... eu vou eu fui para esse grupo de oração... onde LÁ... eu faço outros exercícios... por exemplo... falar em público... né?... evangelização evangeliZANdo... numa praça como tem a praça do LiCEU... eu vou... e falo... no iNÍcio eu tinha que escrever Tudo que eu ia dizer... e eu num podia sabe? Tirar a vista daquilo que eu estava... lendo porque... SE EU tirasse... eu num sabia mais o que... dizer... ficava parada... hoje não graças a Deus $\{$ eu:: me $]$

(Conversação espontânea, D2-39)

Em estudo específico sobre as funções do marcador discursivo "então", Risso (1996, p. 438) destaca que o emprego desse marcador no fecho geral de um tópico está também associado à reiteração de um ponto de vista já manifestado em momentos anteriores. "O efeito é o de uma conclusão fortemente respaldada em todo o pronunciamento anterior, que lhe serve de suporte". Relacionando essa questão com o que ocorre no exemplo (04), percebi que, no estabelecimento de uma relação de acatamento, pode ocorrer também um auto-posicionamento do locutor em relação ao teor de verdade da informação. Ao se posicionar em relação à certeza da informação, reativando-a de forma resumida, a professora também sinaliza para os alunos interlocutores um grau maior de importância que eles devem dar a essa informação. É nesse sentido que o acordo e o auto-posicionamento constituem fatos interacionais.

[3 é o caso de Morte e Vida Severina... "um AUto medie-val... auto medieval... transPOSto para o Nordeste brasileiro... MOStra bem a preocupação de João CaBRAL... em não ficar dis-TANte das formas RIcas... e tradicionais da poeSIa... mas NUNca as repetindo nunca as imiTANdo... e faz exatamente aqui... a estilização do proCEsso... como OUtros poetas já haviam FEIto... desde a época madieVAL... a nossos dias... é sabido que o AUto tem um 
sentido religioso... sem falar no seu arraigado sentido Étido... no caso de João Cabral ele nada mais quis mostrar... do que situar no Nordeste a crucificaÇÃO... do retiRANte e do trabalhador do EIto... em MORte e Vida SeveRIna... as preocupações de João Cabral vão além da estrutura meLÓdica... ou lingüística... quando situa como nenhum outro poeta brasileiro... o HOmem e a TErra... o homem sem POUso no Nordeste... que é o HOmem que se sente PRÓximo... à MORte... e proCUra" eh "um itinerário... a lingua-gem é ainda medieval daí o paralelismo com o mundo nordesTIno... onde se acenTUa/ a GLÓria... e o heroÍSmo do anti-herói nordes-tino"... então realmente... MORte e Vida Severina... AUto de Natal pernambucano AUto... é exatamente uMA:.... uma eh:: o teAtro medieVAL... nós encontramos... eh algumas esPÉcie/ do teatro medieVAL... que é exatamente o AUto... e as farsas né?... a gente sabe que:: em Portu GAL foi Gil Vicente... o criaDOR do teatro popular... MAS existia é:: é criando sempre seus AUtos... né?... autos da Trilogia das BARcas... e algumas FARsas né?... foi Gil Vicente que ao... foi o fundador do teatro potuguês... né?... NA:: EsPAnha Juan del Cina... seria o grande MEStre do teatro espa-NHOL ... e exatamente AUto foi uma espécie de eh do teAtro medieVAL... e Ela exatamente ela tem ela na sua origem... eh:.... o teatro popular... é:: os AUtos cles têm:: uma origem religiosa... né?... o teatro popular antes de ser... eh:: proFAno... ele foi religioso... liGAdo à vida dos santos à vida de Cristo né?... daí porque os autos... muito voltados para a:: vida... eh dos SANtos... e a própria vida de Cristo né?...

(Aula, EF-56)

\subsection{Retomada tópica}

Um marcador discursivo efetua a retomada do tópico após a quebra da lincaridade discursiva por uma inserção. O movimento textual-interativo, nesse caso, está associado à classe e à função dos parênteses. 
Segundo Jubran (1999), as inserções parentéticas podem ser agrupadas em quadro classes, conforme estejam relacionadas à elaboração do tópico, ao locutor, ao interlocutor ou ao ato comunicativo em si. Em cada uma dessas classes, a autora identifica diferentes funções. Por exemplo, um parêntese relacionado à elaboração do tópico pode ser utilizado na focalização do conteúdo, através de exemplo, esclarecimento, ressalva; na formulação lingüística do tópico, num processo de explicitação do significado de palavras, de busca de denominação; e na construção textual, através da marcação de subdivisōes de um tópico.

Quanto mais os parênteses se afastam do enfoque da elaboração tópica mais o processo de retomada é feito através de um marcador. Ao darem relevo à elaboração do tópico (principalmente quando focalizam o conteúdo), os parênteses atenuam a propriedade de desvio tópico, e, dessa forma, acaba se diluindo a idéia de retomada. Como o desvio é pouco saliente, a possibilidade de haver uma marca textual para a retomada é também menor.

No exemplo (05), o trecho em itálico constitui um parêntese que focaliza o conteúdo através de um esclarecimento. O foco é o próprio tópico e, como o desvio é pouco perceptível, o movimento de retomada não apresenta nenhuma marca textual. Já no exemplo (06), existe um parêntese, também em itálico, relacionado ao ato de comunicação em si, ou seja, um desvio que provoca "uma mudança de planos de centração sobre o tópico discursivo para o ato de interagir verbalmente" (JUBRAN, 1999, p. 35). No caso, uma locutora questiona a predisposição da outra para a conversa, a partir da avaliação de que ela está tendo pouca participação no diálogo e pouco envolvimento com os assuntos abordados.

A locutora salienta, por meio do parêntese, que essa predisposição e envolvimento são contingências necessárias para a existência do ato de comunicação. Com o parêntese, o tópico Política, iniciado no segmento 34, com o subtópico Resgate da cidadania, é notoriamente suspenso. No segmento 35 , começa a ser desenvolvido 
o subtópico Conscientização política dos alunos de Inf.1, que põe novamente em evidência o tópico Política. O movimento de retomada é sinalizado pelo marcador "então".

[3 A maioria das legislaçōes antitruste no mundo se fundamentou no Sherman Act, de 1890. A tradiçāo democrática americana alimentava aversão a quaisquer grupos que parecessem ter posição dominante no mercado. Era a época dos "robber barons", que mais tarde Theodore Roosevelt, num arroubo populista, chamaria de "malfeitores de grande fortuna". Era uma visão estática, que não compreendia como a concorrência se desenrola no tempo e é afetada pelas mudanças tecnológicas, pela variação nas preferências dos consumidores, e pela sempre cambiante oferta de importações competitivas.

Desde então o mundo mudou. Com a globalização dos mercados e a revolução tecnológica, novos conceitos surgiram em lugar dos tradicionais "grau de concentração" ou "domínio do mercado". Surgiram conceitos mais sofisticados, como a "elasticidade de substituição" e "contestabilidade". Como no ditado popular, "tamanho não é documento" (exceto no raríssimo caso de produtos insubstituíveis). Qualquer açambarcador do mercado local pode ser "contestado" pela abertura a importações. (...)

(Artigo de opinião, E-149)

Inf. 1 - é porque não comprava mas o pai paga... o feijão que você compra... ele tem também... imposto... você paga... então você num num... acabar com a iDÉia de que... o goVERno... o governo dá o governo num dá nada... nós... temos diREItos... a tudo isso nós temos direito adquiRIdo... por sermos cidadãos... né? a nossa cidadania consiste Nisso... PRImordialmente... nisto... depois 
enTÃO... nós temos a obrigação de... votar::... com esses... esses desMANdos que s/ que existe AÍ... nós Temos o direito e a obrigaÇĀO...DE... repudiAR... de::.... eh protestar contra isso...e nós ficamos calado... então por QUE isso?... porQUE o brasileiro aINda não se conscientizou de que é brasileiro e de que este país é dele... ele PENsa... por causa... também isso... mas também eu tô falando demais né? D.? e tu nem estás falando né?-...

Inf.2-é \{mas não pode deixar... eu trabalho a Português

Inf.1 ((risos))

Inf.2- ...num é que fala mais ou menos $\{(($ risos $)) \ldots$ ah ah

Inf.1- ((risos)) ... pois é ... ] [35 então eu... eu acho assim eu vejo eu analiso e eu falava muito às vezes eu ia falar uhn... ensinar Português para os meus alunos né?... e eu... fazia uma digressão eu saía do da:: do Português e passava pra política... U::I mas os alunos gosta::vam... então os da oitava série como adorava... eh:: enTÃO uma vez um chegou pra mim e disse assim "olha... professora... EU... votei no Lula... por causa da senhora” eu digo "pelo amor de Deus num diga isso "eu nunca disse a você que fala/ ((falou rindo))

(Conversaçāo espontânea, D2-39)

\subsection{Mudança tópica}

Em contexto de mudança de tópico, a função dos marcadores discursivos é realizar o processo textual de ligar, na linearidade do texto, dois quadros tópicos que podem ocupar ou não o mesmo plano na hierarquia da organização tópica do texto, ou dois subtópicos no interior de um mesmo quadro tópico. Nesse processo textual, ocorre também o movimento interacional através do qual o locutor orienta seu interlocutor para a entrada de um novo tópico no discurso, não atinente ao que está sendo desenvolvido. 
Na conversação espontânea D2-30, por exemplo, são desenvolvidos diversos tópicos hierarquicamente independentes. Os tópicos Fortal, Política e economia, Trabalho, Cinema, Pegadinhas do Programa Topa tudo por dinheiro, não apresentam entre si nenhuma relação de dependência. Eles surgem naturalmente na conversa, a partir dos diferentes interesses dos locutores.

Para não transcrever todo o texto, dada a sua extensão, apresento em (07) apenas os trechos de transição entre os supertópicos, cuja articulação é feita por meio de um marcador. A articulação entre os tópicos Fortal e Política e economia (no segmento 4) é feita pelos marcadores "bom" e "agora". No segmento 7 , também o marcador "agora" realiza o movimento textual de ligação entre os tópicos Política e economia e Trabalho. Finalmente, a articulação entre os tópicos Hábitos do homem moderno e Pegadinhas do Programa Topa tudo por dinheiro, no segmento 18, realiza-se pelo marcador "por sinal". Nos três casos, através do movimento textual que articula os tópicos, o locutor orienta seus interlocutores para a mudança de centração, ou seja, a partir do ponto em que o marcador é empregado um novo conjunto de referentes concernentes entre si entra no discurso.

A mudança é desencadeada por diferentes fatores interacionais (AQUINO, 1991). No exemplo em questão, o tópico Fortal apresenta sinais de esgotamento. No final do segmento 2, subtópico O bloco Sirigüela, após a inserção do segmento 3 , subtópico Perído do evento, as repetições "quatro mil pessoas é::...." e "é uma escola de samba do Rio de Janeiro..." sugerem que, para os locutores não há mais o que dizer sobre esse tópico. No ponto da conversa em que ocorre a passagem do tópico Política e economia para Trabalho, parece ocorrer um desinteresse por parte do informante 1 sobre a falta de hábito da informante 2 de ler jornal, questão que desencadeia um parêntese, pois não chega a ser desenvolvida. Essa falta de interesse motiva a mudança. Já o tópico Pegadinhas do Programa Topa tudo por dinheiro emerge na conversa por decorrência do anterior. No segmento 17 , tópico paralelo Hábitos do homem moderno, a informante opina sobre 
a forma de vestir dos homens, que pode comprometer a masculinidade. Essa questão a faz lembrar de um programa de televisão em que uma mulher aparece vestida de homem, o Programa Topa tudo por dinheiro, que passa a ser o novo foco da conversa. Essa relação de associação entre os tópicos é inclusive manifestada pelo emprego do marcador "por sinal".

Fortal x Política e economia

Inf. 1 - agora quantos componente tem o Sirigüela? e os e quanto segurança tem?...

Inf. 2 - ah eu num sei mas eu escutei alguma a respeito de:: novecento segurança foi?... foi \{tu que

me disse?

Inf. 1 - foi foi eu vi que ia ter TRÊS MIL...

Inf. 2 - três mil

Inf. 1 - três mil e cem...

Inf. 2 - pe\{ssoas né?

Inf. 1 - quem me disse foi o::... o dono LÁ do::... com/é o nome?... o besame mucho é?...

Inf. 2 - Besame mucho $\{E H$ tem esse barzinho tem esse barzim

Inf. 1 - EH besame mucho que falou que eram três mil e cem onde Itava a sua amiga T. lá T. ((riu))

Inf. 1 - nunca ouvi falar ()

$\operatorname{Inf} .2-T$.

Inf. 1 - pois é aí ele me falou que eram TRÊS mil e cem... e:: novecento segurança...

Inf. 2 - mas os três mil e CEM mais novecento segurança dá quatro mil pessoa \{dentro duma corda só 
Inf. 1 - dá quatro mil pessoas ...eu até falei pra Ele que QUAtro mil pessoas... seria::... uma escola de samba do Rio de Janeiro...

Inf. 2 - é meu filho é mais ou \{meno/ por aí

Inf. 1 - é

Inf 2 - o negócio é animado veja bem... /ta pensando o quê

Inf $1-(($ riu $))$

Inf $2-(($ riu $))$

Inf 1 - \{quatro mil pessoas é::.....

Inf 2 - ((riu)) é::

Inf 1 - é uma escola de samba do Rio de Janeiro...

Inf 2 - é...exatamente...

Inf 1 - [4 bom... agora... quem é que voCÊE.:... quem é que você vai votar $\mathrm{pa} /$ presidente?

Inf $2-\{(($ risos $))$

Inf 1 - você num ((falou rindo))

Inf 2 - ... hoje eu/tava hoje eu/tava dizendo pro:.... pro menino lá que eu te falei... que eu chamo ele de petista né? (...)

Política e economia x Trabalho

Inf. 1 - ...e o salário né?

Inf. 2 - e o salário a \{inda por cima

Inf. 1 - ah sim

Inf. 2 - o saLÁrio... tem TUdo isso e o salário... fica hospedada na sua casa... pelo meno/ EU trato muito bem... pode ser até que tenha CAsa aí que num trate mas eu acho... mas num querem:: num quer trabaLHAR... num querem saber de nada... ficam naquelas poBREza na miséria lógico... problema delas... que que a gente pode fazer?... a gente até que TENta tal e tal... lógico que existe as fatalidades como aquele caso da Irlan né? Irlan 
Inf. 1 - é

Inf. 2 - \{que a mulher matou a pobre da doméstica né? que foi... Inf. 1 - que matou a::

Inf. 2 - tempos e tempo que eu acompanhei no jornal... quase todo dia saía uma pontinha sobre aquilo... MAS... o que se pode fazer lógi $\{$ co::

Inf. 1 - há tempo que /cê num lê jornal né?...

Inf. 2 - tempo que eu leio jornal lá na sala ao lado... NÃO agora eu leio eu tenho direito ao

Diário do Nordeste agora eu leio... esse é o meu hoRÁrio de ler jornal...

Inf. 1 - [7 agora qual é o trabalho que /cê faz aqui no SINE...

Inf. 2 - AH:: ((risos)) o meu trabalho AH:: H. é tão::... é muito diversificado...

Inf. 1 - o que é a O \& M? o que é?

Hábitos do homem moderno x Pegadinhas do Programa Topa tudo por dinheiro

[17 Inf. 2 - é igual à história hoje eu dizendo pra pra pra... E. né? dizendo pra E. que aCHAva... que HOmem pra mim que usa... cabelim de rabo né? cabelo grande cabelo grande é pa/ mulher homem HOmem que é macho macho que é MAcho ele não usa brinco... ele não usa cabelo GRANde nem ele usa macacão... macacão que eu digo n/é macacão bombeiro de posto não macacão aqueles macacão jeans assim ((riu)) sabe? ((falou rindo))... então MAcho que é MAcho... assim por exemplo um PAI meu você:: o $M$. meu irmão $M$. o povo que eu conheço jamais... olhe que eu conheço macho muito macho... mas esse negócio \{desse po/ Inf. 1 - macho muito macho

Inf. 2 - macho muito macho... homem pra mim que tem esse negócio "não:: galera hoje é assim mesmo ( ) e tal vamo/ usar"... 
pode ser que ele nem seja eu já /tô é generalizando já/tô dizendo que é tudo veado... mas pra mim é que eu jamais iria namorar com um homem cutucar ele aqui... sentir o brinquinho e os cabelo grande maravilhoso jamais... Deus me livre... \{quero distância... rabo de cavalo lá vem...

Inf. 1 - rabo de cava::lo

Inf. 2 - já imaginou hoje em dia eh/tá tudo trocado hoje em dia eh /tá tudo trocado hoje em dia os homem têm o cabelo grande as mulher /tão pelando as cabeça... imaginou... um/tar se agarrando com outro aí um passa a mão no outro não::... \{gosto disso não Inf. 2 - vai saber

Inf. 1 - ...não... [18 por sinal tu viu o Sílvio Santo?... domingo?

Inf. 1 - ... não

Inf. 2 - aquele Topa tudo por dinheiro $(($ riu $)) \ldots$ a aí tinha uma artista ((falou

rindo))

Inf. 1 - que foi

Inf. 2 - /cê viu? não... tinha uma artista... daquelas de Sílvio Santo né?... ela se vestia todinha de homem de PASta executivo e tal terno gravata bigode /tá /tá... aí ia p/ o meio da rua aí de repente chegava um cara que também é::... do elenco lá do SBT... aí diz "oh:: querida há quanto tempo" aí abraÇAva e beiJAva né? o maior agarrado do mundo... e o povo que ia passando no meio da rua... pensava que Era... que eles dois eram:: na\{morados

(Conversação espontânea, D2-30)

Um marcador discursivo pode ainda assinalar conjuntamente a mudança de tópico e a mudança de modo discursivo, de declarativos a interrogativos, de narrativos a avaliativos, por exemplo. É o que ocorre na articulação tópica destacada no exemplo (08). O trecho 
compreende dois subtópcios do quadro tópico Adiministração pública. No segmento 13, tópico O ex-governador Tasso Jereissati, os informantes discorrem sobre a atuação política do então e ex-governador do estado do Ceará. No segmento 14, tópico Problema do serviço público, um dos informantes se centra no serviço público. Um novo conjunto de centração é, então, aberto, e ocorre também uma mudança de discurso narrativo para avaliativo. $\mathrm{O}$ tópico $O$ ex-governador Tasso Jereissati é predominantemente narrativo, porque centrado nos feitos do governador ("na Secretaria de CulTUra... ele fez....", "trouxe TÉCnico trouxe GENte", "ele FEZ... deixou PRONto... o Museu do Ceará"). Já no tópico Problema do serviço público, não ocorre narração de fatos, mas julgamentos, impressões dos locutores sobre os fatos. Nesse segmento, é bastante recorrente, inclusive, o marcador de opinião "eu acho que".

\section{[13 Inf. 2 - \{porque os}

Inf. 1 - os nossos candidato que /tão aí /cês acham que:.... são bons?... nós temos boas opções aí?... nas eleições?... PRA governador?...

Inf. 2 - pra governador... eu acho...

Doc.1- que que /cê acha?...

Inf. 2 - eh:: eu votaria no Tasso... eu votaria... nele

Doc.1- \{por quê?

Inf. 2 - num tenho nada num tenho nada contra ele não... num acho que::

Inf. 1 - é... o \{governo

Inf. 2 - tenho

Inf. 1 - do Tasso o priMEIro goVERno... o Tasso fez um governo até::... bom

Inf. 2 - foi... 
Inf. 1 - foi... em TERmos por exemplo... lá da minha secretaria onde eu trabaLHAva... na Secretaria de CulTUra... ele fez... PAra a Secretaria de Cultura... ele fez um exCELENte governo... trouxe aquela Maria A:.... Violeta ARRAes... e em TERmos DE Secretaria de Cultura que eu... posso falar só no daquilo que eu entendo né? os número de economia tal... o pessoal pode até MAIS... Secretaria de Cultura funcioNAva... em CIma... da biblioteca então nã/ num existia Secretaria de Cultura era um:.... um poLEIro lá em cima da... da Biblioteca Pública... CHEIo de vazamento quando chovia o pessoal botava esse cesto de lixo pingando... na HOra que ela chegou disse "não isso aqui né? Secretaria de Cultura... eu quero o Palácio da Abolição"... aí NÃO num sei o que deram a metade do palácio...

Inf. 2 - eh já mudou né?

Inf. 1 - já muDOU... "eu quero"... só tinha um carro... "eu quero num sei quantos carro eu quero reformar o palácio todo"... quer dizer a secretaria que ocupava... umas:: OIto ou nove salas... hoje ocupa umas TRINta ou quarenta salas... e AÍ trouxe TÉCnico trouxe GENte né?... ela:.... reformou o Teatro José de Alencar... TOdo... dizem que foi três milhões de dólares... ela reformou o Palácio da Luz... ELA:.... conseguiu faZER... o arquivo público... que o Tasso deixou e o Ciro deixou acabar e teve que refazer de novo porque não usaram o TEMpo... ficou tanto tempo fechado que tiveram que fazer de novo...

Doc. 1 - ((ri))

Inf. 1 - né?... ele FEZ ... deixou PRONto... o Museu do Ceará... que s/ que DEMOROU tanto pa/ inaugurar que o Ciro teve que pintar de novo porque já/tava sujo mas foi Ele que fez né?... eu digo sempre que o s/ o Tasso fez e o Ciro acabou né?...

Inf. 2 - é

Inf. 1 - quer dizer então o o TOdos os PRÉdios que a Secretaria de Cultura TEM... ele reformou todos... TOdos que foi o o Arquivo Público o Teatro José de Alencar o Museu do Ceará o Palácio da Luz... Academia Cearense de Letras... eh o Palácio da Luz Palácio da Abolição... né? tudo tudo tudo ele fez... e deixou 
pronto... e Ela quis implantar aqui a história do::... com o FestRio... a história do cinema no Ceará... que achava que o CeaRÁ que é o Estado do Brasil onde tem MAIS luz durante o ano né?... comparado com todos os Estado do BraSIL...

(...)

Inf. 1 - $\quad$ enTÃO... É então já ela e/ ela... conseguiu aí o TErreno conseguiu tudo mais... a época parece que num foi muito propícia criOU... um departamento SÓ pra cuidar disso... se investiu MUIto ((fim do lado A))

Doc.2- $\{$ /tava falando ai do Tasso Jereissati da da e

Inf. 1 - ((tosse))

Inf. 2 - cinema...

Inf. 1 - eh \{então ele ela ela ela criOU LÁ... um departamento de A)

Inf. 2 - ((tosse $)) \ldots$ - Itá saindo a tosse?...

Doc.2- po $\{d e$

Doc.1- eu $\{$ transcrevo

Inf. 1 - ((ri))

Inf. 2 - mas $N \tilde{A} O$...

Inf. 1 - ((ri))... \{ essa tosse é conhecida dela... ela ela

Inf. 2 - ((tosse))

Inf. 1 - criOU...

Inf. 2 - ((tosse $))\{(($ tosse $))$

Inf. 1 - um departamento de ÁUdio-visual... né?... ele é esse departamento de áudio-visual que é uma era uma... funcionava na Casa da::... Vice-governadoRIA em frente o PaLÁcio... era colocou lá uma::... uma videoteca... ((voz de estranho))

Inf. 2 - ...NAda num conseguiu não... ((voz de estranho))

Inf. 1 - uma:: 
Inf. 2 - foi... por quanto...((voz de estranho)) cento e oitenta rea/ ((ruído))

Doc.1- pode falar sobre o SINE também se qui $\{$ serem dizer com/ é que é viu?...

Inf. 1 - $\quad$ certo tudo bem... tem muito chão $\mathrm{pa}$ / frente

Inf. 2 - raPAZ mais trinta minutos \{aí... falando

Inf. 1 - $\quad(($ riu $))$ fala do \{SINE da vida alheia de tudo... então ele criOU

Inf. 2 - fala... é::... ( )

Doc.1- ((ri))

Inf. 2 - \{assim /tá ( )

Inf. 1 - ele criOU A::...

Doc.2- videoteca né? a a \{videoteca

Inf. 1 - a:: DENtro... desse departamento de áudio-visuAL... ele criou uma videoTEca... que é exatamente... você... tem lá VÍdeos... você PEga:: gratuitamente só ir lá pegar... que são temas... de filmes conhecidos... E você tem uma::... uma::... discoteca... que seria de discos... mas não discos... de mú::sica popular um disco mais de... jingle de propaganda... eh:: arquivos do:.... de RÁdios da cidade né?... e:: uma filmoteca também formado por:.... filmes de propaganda da:: TV Ceará antiga TV Ceará...

Inf. 2 - ((tosse $))$

\section{(...)}

Inf. 1 - enTÃO... eh:: ele CRIOU ela criou tudo isso...] [14 agora quer dizer $\mathrm{pa} /$ você aí teve TOdo o... a

equipe... TÉCnica... e TOdo o material foi comprado só que /tá lá tudo parado isso... não funciona nada... \{PORQUE

Inf. 2 - olhe só

veja bem...

Inf. 1 - eu Acho que essa PARte... SÓ SÓ SÓ 
Inf. 2 - éfinalizan $\{$ do

Inf. 1 - só terminando \{aqui eu

Inf. 2 - né? o

Inf. 1 - acho que essa parte

Inf. $2-\{(($ tosse $))$

Inf. 1 - o serviço público.. de... de um modo GERAL... NÃO aqui no SINE porque o o diretor que começou é o que está até hoje... então num HÁ::... QUEbra de:: solução de continuidade né?... quer dizer o cara começa e termina mas o serviço público tem muito Inf. 2 - ... \{com o quê?

Inf. 1 - é muito parecido com o mar... é chei/ de ONda né?... \{então CADA S/ CADA... cada secretário

Inf. 2 - então uma hora /tá em cima outra hora /tá em baixo

Inf. 1 - que EN tra tem uma onda então o cara "bom... VAmo/ faZER uma:... hemeroteca"... aí pronto aí pega tudo quanto é de jornal aquele negócio todo né?... "vamo/ fazer o departamento de ÁUdiovisual"... aí... aí faz aquele negócio todo... "vamo/ fazer o muSEU da imagem e do som"... aí FAZ aquele negócio então CADA UM...

Inf. 2 - vai fazer alguma coi $\{$ as

Inf. 1 - vai faZENdo e vai quebrando os que ficam atrás né? quer dizer aquela idéia do de trás... tudo bem que ele faça a idéia dele mas que num aCAbe...\{com a idéia do outro

Inf. 2 - com a idéia do outro

Inf. 1 - \{esse eu Acho que o serviço público tem muito disso né?...

Inf. 2 - isso é verdade... é

Inf. 1 - você desPREZAR o que foi feito...

Inf. 2 - é

Inf. 1 - veja BEM diga lá] 


\section{Considerações finais}

A análise aqui apresentada destacou a dupla função dos marcadores discursivos: organizar segmentos tópicos e enunciados na linearidade do texto e sinalizar aspectos do processo interacional. Alguns dos estudos sobre articulação do texto pautados na noção de conectivos, como se detêm apenas à estrutura do texto, sem referências às motivações pragmáticas, atribuem ao marcador a função de estabelecer os diferentes tipos de relações que ocorrem entre partes do texto. Conforme mostram os resultados aqui apontados, as orientações de sentido bem como os demais objetivos interacionais que se congregam à função articuladora de um marcador são construídos no e pelo discurso. E por isso não são inerentes à relação entre segmentos tópicos ou enunciados ou ao próprio marcador.

Isso vai ao encontro do argumento de Neves (2003, p. 75) segundo o qual as noções básicas da Lingüística do Texto, mais, rigorosamente, textual-interativa, estão contidas nas propostas teóricas do Funcionalismo Lingüístico. "O que se faz nas propostas funcionalistas é falar de gramática falando de funcionamento e de funções, é configurar a gramática olhando para além da expressão lingüística." É exatamente isso o que ocorre no caso particular da análise do uso de marcadores discursivos. Trata-se, no meu entendimento, de uma gramática do texto em que as regras organizacionais relacionadas ao movimento de articulação de suas partes, segmentos tópicos, na perspectiva aqui adotada, emergem no processo interacional. 


\section{Referências}

AQUINO, Z. G. O. Mudança de tópico no discurso oral dialogado. Dissertação (Mestrado em Ciências Humanas: Língua Portuguesa), Pontifícia Universidade Católica de São Paulo, São Paulo, 1991.

JUBRAN, C. C. A. S. Estratégias de construção textual - parentização. 1999. Mimeografado.

KOCH, I. G. V. et al. Proposta teórica do grupo de organização textual-interativa to projeto de Gramática do Português Falado, 1994. Mimeografado.

NEVES, M. H. de M. Funcionalismo e Lingüística do Texto. Revista do GEL, v. 1, no 1, 2003.

PINHEIRO, C. L. Integração de fatos formulativos e interacionais na construção do texto: um estudo a partir da topicalidade. Tese (Doutorado em Letras), Universidade do Estado de São Paulo, Assis-SP, 2003.

RISSO, M. S., SILVA, G. M. de O. \& URBANO, H. Marcadores discursivos: traços definidores. In: KOCH, I. V. (org.). Gramática do português falado. Vol VI, Campinas/SP: UNICAMP, São Paulo: FAPESP, 1996.

RISSO, M. S. O articulador discursivo “então”. In: CASTILHO, A. T. de (org.). Gramática do português falado. Vol IV. Campinas/SP: UNICAMP; São Paulo: FAPESP, 1996. 